\title{
The proangiogenic potential of a novel calcium releasing composite biomaterial:
}

orthotopic in vivo evaluation

Hugo Oliveira ${ }^{1,2}$, Sylvain Catros ${ }^{1,2,3}$, Oscar Castano ${ }^{4,5,7}$, Sylvie Rey ${ }^{1,2}$, Robin Siadous ${ }^{1,2}$, Douglas Clift ${ }^{4,5}$, Joan Marti-Munoz ${ }^{4,5}$, Marc Batista ${ }^{4,5}$, Reine Bareille ${ }^{1,2}$, Josep Planell ${ }^{4,5,7}$, Elisabeth Engel ${ }^{4,5,6}$, Joëlle Amédée $e^{1,2}$

${ }^{1}$ University of Bordeaux, Tissue Bioengineering, U1026, F-33076 Bordeaux, France

${ }^{2}$ Inserm, Tissue Bioengineering, U1026, F-33076 Bordeaux, France

${ }^{3}$ CHU Bordeaux, Services d'Odontologie et de Santé Buccale, F-33076 Bordeaux, France

${ }^{4}$ Biomaterials for Regenerative Therapies' Institute for Bioengineering of Catalonia (IBEC), Barcelona, Spain

${ }^{5}$ CIBER en Bioingeniería, Biomateriales y Nanomedicina, CIBER-BBN, 50018

Zaragoza, Spain

${ }^{6}$ Materials Science and Metallurgical Engineering, Universitat Politècnica de Catalunya, Barcelona, Spain

${ }^{7}$ Materials Science and Physical Chemistry, Universitat de Barcelona, Barcelona, Spain

Corresponding author: Hugo Oliveira.

Address: Inserm U1026 Biotis, Zone Nord, Bât. 4a, 2ème étage, 146 rue Léo Saignat 33076 Bordeaux cedex, France

Telephone: +33(0)5 57571190

Email: hugo.de-oliveira@inserm.fr 


\begin{abstract}
Insufficient angiogenesis remains a major hurdle in current bone tissue engineering strategies. An extensive body of work has focused on the use of angiogenic factors or endothelial progenitor cells. However, these approaches are inherently complex, in terms of regulatory and methodologic implementation, and present a high cost. We have recently demonstrate the potential of electrospun poly(lactic acid) (PLA) fiber-based membranes, containing calcium phosphate $(\mathrm{CaP})$ ormoglass particles, to elicit angiogenesis in vivo, in a subcutaneous model in mice. Here we have devised an injectable composite, containing CaP glass-ceramic particles, dispersed within a (Hydroxypropyl)methyl cellulose (HPMC) matrix, with the capacity to release calcium in a more sustained fashion. We show that by tuning the release of calcium in vivo, in a rat bone defect model, we could improve both bone formation and increase angiogenesis. The bone regeneration kinetics was dependent on the $\mathrm{Ca}^{2+}$ release rate, with the faster $\mathrm{Ca}^{2+}$ release composite gel showing improved bone repair at 3 weeks, in relation to control. In the same line, improved angiogenesis could be observed for the same gel formulation at 6 weeks post implantation. This methodology allows to integrate two fundamental processes for bone tissue regeneration while using a simple, cost effective, and safe approach.
\end{abstract}

\title{
Keywords
}

Angiogenesis, Bone regeneration, Calcium phosphate ormoglasses

\section{Introduction}


Current bone regeneration approaches still face a wide range of limitations, which in combination to the increased incidence of bone pathologies, linked to the increased aging of the general population, continues to pose an important health challenge. Present regeneration approaches are focused on three main strategies: i) autologous bone grafts that, although the gold standard for bone regeneration and the most common approach, implies a two stage, time consuming surgical procedure that requires patients in general good health and is often associated with significant morbidity, post-operative pain, hypersensitivity, infection and paresthesia [1-4]; ii) allogeneic bone grafts, often associated with immunogenic and infection risks [5]; and iii) bone substitutes, based on biodegradable polymers and/or synthetic ceramics, increasingly being studied as bone tissue engineering material as they can be established as an off-the-shelf clinical product [6]. This last approach, although with great potential to satisfy clinical need, has shown insufficient vascularization and osteointegration when in the absence of autologous cells and/or proangiogenic factors [7]. Indeed, attempts to stimulate neovascularization by the use of recombinant protein, angiogenic growth factors gene transfer or endothelial cells have been proposed, however often associated with problems regarding the delivery and duration of exposure to the growth factors and with the survival of endothelial cells [7]. Additionally, due to inherent risks, the use of growth factors and autologous cells presents additional regulatory hurdles, particularly relevant in some cases of bone repair postcancer resection [8]. Hence, in order to fulfill the promise of bone tissue engineering the problematic of neovascularization, inside the implanted constructs, has to be solved in order to reach the bedside. This drawback is particularly relevant in large bone defects, where the amount of oxygen required for cell survival is limited to a diffusion distance between 150-200 $\mu \mathrm{m}$ from the supplying blood vessels [9]. Nonetheless, in view of a broad clinical application, the establishment of off-the-shelf strategies may prove beneficial and reduce regulatory issues. 
As such, the use of synthetic polymeric matrices, that can be readily engineered and custom designed, may show the future for new bone therapeutic approaches.

We have recently demonstrated the potential of electrospun poly(lactic acid) (PLA) fiber-based membranes, containing calcium phosphate ormoglass (organically modified glass-a nanostructured glass containing organic material -Sachot et al. DOI: 10.1098/rsif.2013.0684-) particles) (CaP), to elicit angiogenesis in vivo, in a subcutaneous model in mice [10]. These $\mathrm{CaP}$ particles with capacity to release bioactive calcium ions (from minutes to several hours), in a controlled fashion, are an alternative cost effective approach in order to achieve ready-touse bone substitutes. Based on the observation that rapid increased local concentration of calcium $\left(\mathrm{Ca}^{2+}\right)$ ions could induce the migration, maturation and organization of endothelial progenitors [11], we could demonstrate in vivo that these materials could elicit the local expression of angiogenic factors, associated to a chemotactic effect on macrophages, and sustain angiogenesis into the biomaterial [10].

On the other hand, calcium phosphate glass ceramics are a very promising alternative in order to attain further controlled ion release rates, as crystalline phases show to degrade slower than glassy ones [12]. Our hypothesis is based on the slower and longer healing of the inner part of the bone tissue and thus the required $\mathrm{Ca}^{2+}$ stimulation should be slower and more sustained.

Here, we evaluated the use of a sol-gel prepared $\mathrm{CaP}$ glass-ceramic in an orthotopic model, in a condylar defect in rat, to sustain both bone repair and angiogenesis. We tested different calcination temperatures, in order to tune $\mathrm{Ca}^{2+}$ release profiles, formulated them as an injectable composite and associated it with a PLA/ormoglass contention membrane.

\section{Materials and Methods}

\subsection{Reagents}


Unless mentioned otherwise, all reagents were obtained from Sigma-Aldrich and were of analytical grade.

\subsection{Scaffolds fabrication and characterization}

Sol-gel alkoxide precursor solutions were prepared by refluxing them in proper solvents, except Ti tetraisopropoxide was commercially obtained (ALFA AESAR, 97\%) and diluted in absolute ethanol. $\mathrm{Ca}$ and $\mathrm{Na}$ precursor solutions were prepared by refluxing metallic $\mathrm{Ca}$ and $\mathrm{Na}$ in 2 methoxyethanol. $\mathrm{P}$ precursor solution was obtained by refluxing $\mathrm{P}_{2} \mathrm{O}_{5}$ in absolute ethanol.

\subsubsection{Electrospun PLA mats with embedded NP}

CaP ormoglass NPs were prepared by a partial hydrolyzed alkoxides sol-gel method with a composition of 44.5:44.5:6:5 $\mathrm{CaO}: \mathrm{P}_{2} \mathrm{O}_{5}: \mathrm{Na}_{2} \mathrm{O}: \mathrm{TiO}_{2}$ molar ratio, following a previous report [13]. After mixing $\mathrm{Ca}, \mathrm{Na}$ an $\mathrm{Ti}$ precursor solutions in the proper molar ratio in inert atmosphere, a catalyst with a composition related to $\mathrm{Ti}\left(\mathrm{Ti}: \mathrm{H}_{2} \mathrm{O}: \mathrm{NH}_{3}: \mathrm{EtOH} 1: 60: 0.3: 12\right)$ was added at $4^{\circ} \mathrm{C}$ at $2 \mathrm{ml} / \mathrm{h}$ using an infusion pump. Afterwards, $\mathrm{P}$ precursor was similarly added at $4^{\circ} \mathrm{C}$ and $1 \mathrm{ml} / \mathrm{h}$ flow. The mix turned from dark brown to clear orange and it was subsequently hold at $70^{\circ} \mathrm{C}$ during 4 days for aging and allow the formation of NPs. They were finally collected and washed with absolute ethanol by centrifugation and dried at $90^{\circ} \mathrm{C}$ in the oven.

Nanofiber mats were prepared as previously described [10]. Briefly, PLA nanofibers loaded with $20 \%(\mathrm{w} / \mathrm{w})$ of $\mathrm{CaP}$ ormoglasses (labelled as PLA CaP) were prepared by the ultrasonic dispersion of the nanoparticles in a 4\% (w/v) PLA (Purasorb PLDL 7038, inherent viscosity midpoint $3.8 \mathrm{dl} / \mathrm{g}$, molecular mass $\approx 850,000 \mathrm{Da}$ ) solution. Slurries were electrospun at $8.000 \mathrm{~V}$, $150 \mathrm{~mm}$ distance tip-collector and at $1200 \mathrm{rpm}$ rotary collector speed.

\subsubsection{Nanostructured G8 glass-ceramic injectable gels fabrication}


To prepare the glass-ceramic material $\mathrm{Ca}, \mathrm{Na}$ and $\mathrm{Ti}$ precursor solutions were mixed in inert atmosphere in the proper molar ratio, similarly to previous process. $\mathrm{P}$ precursor solution was then added at $4^{\circ} \mathrm{C}$ and a rate of $2.5 \mathrm{~mL} / \mathrm{h}$ using an infusion pump. Then, an acid aqueous catalyst with a Ti molar relation of Ti:20 $\mathrm{H}_{2} \mathrm{O}: 0.1 \mathrm{HCl}: 5$ isopropyl alcohol was added at a rate of $1 \mathrm{~mL} / \mathrm{h}$ and $4{ }^{\circ} \mathrm{C}$. The mix was sealed and left to rest for 24 hours at room temperature and then heated at $80^{\circ} \mathrm{C}$ for 3 days. The resulting liquid part was poured and eliminated, and the solid gel heated at $120^{\circ} \mathrm{C}$ for 12 hours at air. The resulting powder was grounded and hold to a thermal treatment at 500, 540, 570 or $610^{\circ} \mathrm{C}$ (labeled as CaP 500, CaP 540, CaP 570 and CaP 610) for 5 hours. The final powder was milled and sieved to obtain sintered nanoparticles agglomerates smaller than $40 \mu \mathrm{m}$.

(Hydroxypropyl)methyl cellulose (HPMC, Mn 90000 Da, Sigma) was dissolved in Phosphate buffer saline (PBS) to a final concentration of $2 \%(\mathrm{w} / \mathrm{v})$ and sterilized by autoclaving. In order to formulate the composite gel, $40 \%(\mathrm{w} / \mathrm{v})$ of $\mathrm{CaP}$ particles were dispersed in the HPMC gel, under gentle orbital inversing mixing, overnight at room temperature.

Both constructs, produced as stated in sections 2.2.1 and 2.2.2, were then combined for the in vivo assays.

\subsection{Calcium release, FE-SEM characterization, chemical composition and Brunauer, Emmett and Teller (BET) surface area..}

Calcium release from the glass-ceramics powders was measured using an ion selective electrode. 3 replicas for each time point and sample of $15 \mathrm{mg}$ of glass or glass-ceramic powder samples were bathed in $750 \mu \mathrm{L}$ of $0.01 \mathrm{M}$ HEPES buffer solution and incubated at $37{ }^{\circ} \mathrm{C}$. Bathing fluid was removed periodically (every 3-4 days) for a period of 36 days and $\mathrm{pH}$ and calcium ions were measured in the removed solution. $\mathrm{pH}$ was measured with a Crison GLP22 (Crison, SPAIN), while electrical potential of the solution was measured with a combined calcium selective polymer-membrane electrode (Metrohm AG, Herisau Switzerland). Electrical 
potential values read from the solution were compared to measurements from calibration solutions to determine calcium concentrations of the samples.

Micro- and nano-morphology was measured using an Ultra-High Resolution Field Emission Scanning Electron Microscopy (Nova Nano SEM-230; FEI Co., Netherlands), operating at 5.00 $\mathrm{Kv}$ and coating the samples with an ultra-thin layer of carbon to make them conductive.

Material's composition was assessed using an Energy Dispersive X-ray Spectrometer (EDS, Quanta 200 XTE 325/D8395; FEI Co.). Materials were also coated with a thin layer of carbon before analysis.

BET measurements were carried out on a BET ASAP 2020 (Micrometrics, USA). Samples of around $300 \mathrm{mg}$ for each calcination temperature were firstly degasified during $24 \mathrm{~h}$ at $150^{\circ} \mathrm{C}$. Equilibration interval was of 30 seconds and the relative pressure $\left(\mathrm{P} / \mathrm{P}_{0}\right)$ was ranged from 0.1 to 0.8 . Cold free space values were around $47.5 \mathrm{~cm}^{3}$.

\subsection{Glass transition temperature and simultaneous thermogravimetric (TGA) and differential thermal analysis (DTA).}

Glass transition temperature was measured on a Q20 differential scanning calorimeter (TA instruments, USA). A heating rate of $10^{\circ} \mathrm{C} / \mathrm{min}$ to $600{ }^{\circ} \mathrm{C}$ was used. Simultaneous thermogravimetric and differential thermal analysis of the sol-gel sample was executed on a Netzsch STA 409 C/CD instrument (NETZSCH-Gerätebau GmbH, Germany). A heating rate of $10^{\circ} \mathrm{C} / \mathrm{min}$ to $900^{\circ} \mathrm{C}$ was used.

\subsection{X-ray diffraction}

XRD was measured on a PANalytical X'pert PRO MPD Alphal powder diffractometer. Patterns were collected from $2 \theta=4.2$ to $80^{\circ}$ with a step size of $0.017^{\circ}$ and a measuring time of 50 seconds per step. 


\subsection{Organic Elemental Analysis}

Powder glass-ceramic samples were analyzed after heat treatment to determine residual carbon using a Carlo Erba Instruments Thermo Flash 2000 (Carlo Erba, Milan, Italy). This method is based on a Gas chromatography after total decomposition and oxidation of the sample at high temperature $\left(\sim 1800^{\circ} \mathrm{C}\right)$. For that purpose, 100mg samples were used.

\subsection{Cell culture}

Human progenitor-derived endothelial cells (PDECs) were obtained as previously described [14]. Briefly, human umbilical cord blood from healthy donors (between 20 and 35 years) were diluted with one part of PBS, 2\% (v/v) fetal calf serum (FCS) and $2 \mathrm{mM}$ ethylene diamine tetraacetic acid (EDTA), and applied to a density gradient centrifugation in Histopaque ${ }^{\circledR}$ solution $\left(1.077 \mathrm{~g} . \mathrm{mL}^{-1}\right)$. Mononuclear cells were recovered from the buffy coat, washed several times with PBS and cultured in endothelial cell growth medium-2 (EGM-2; Lonza-Verviers, France) containing all kit supplements and 5\% (v/v) FCS (GIBCO Life Technologies, Karlsruhe, Germany), on collagen-coated 12-well plates (collagen type I from rat tail, BD Biosciences) and at $5 \times 10^{7}$ cells per $\mathrm{cm}^{2}$. At day 4, non-adherent cells were removed and medium was refreshed every other day. After 2-3 weeks, cobblestone-like morphology colonies were harvested, using $0.25 \%(\mathrm{w} / \mathrm{v})$ trypsin-EDTA (GIBCO) and subcultured in fresh collagencoated dishes. Cells were expanded over several passages, using standard cell culture procedures.

\subsection{In vitro evaluation}

Twenty-four hours prior, PDECs were seeded on 24 well plates at $20 \times 10^{3} / \mathrm{cm}^{2}$ and cultured using $500 \mu \mathrm{L}$ of endothelial cell growth medium-2 (EGM-2; Lonza-Verviers, France). Then, $50 \mu \mathrm{L}$ of HPMC gels, containing $40 \%$ (w/v) of $\mathrm{CaP} 540$ or CaP 570 particles, were placed inside a $0.4 \mu \mathrm{m}$ pore transwell (Corning, EMEA, France) and set in contact with the cell culture 
medium. At designated time points cells were processed for viability assay or cells culture medium was assessed for VEGF quantification.

\subsection{Cell viability assessment}

Cytotoxicity assessment on human PDECs was performed according to the standard ISO/EN 10993, part 5, guidelines and using the neutral red assay at $48 \mathrm{hrs}$ post plating. Briefly, $24 \mathrm{hrs}$ post exposure to the HPMC gels, through the transwell inserts, the colorimetric neutral red assay was performed according to established protocols [15].

\subsection{VEGF secretion evaluation}

In order to assess the capacity of the different materials to induce the secretion of vascular endothelial growth factor (VEGF), the cell culture medium of PDECs cultured on the different materials for 4 days was recovered, snap frozen and kept at $-80{ }^{\circ} \mathrm{C}$ until further use. Secreted VEGF was evaluated by ELISA assay using a commercial kit (human VEGF ELISA, \#DVE00, R\&D Systems, USA) following the manufacturer's instructions.

\subsection{Animal procedures}

As an initial model to assess the capacity of the developed materials to sustain bone repair we implanted them in a bone defect model in rats, condylar defect. All the procedures for rat handling were based on the principles of Laboratory Animal Care formulated by the National Society for Medical Research and approved by the Animal Care and Experiment Committee of University of Bordeaux, Bordeaux, France. Experiments were carried out in accredited animal facilities following European recommendations for laboratory animal care (directive 86/609 CEE of 24/11/86).

Medial holes, $4 \mathrm{~mm}$ diameter and $6 \mathrm{~mm}$ depth were created in both left and right femoral condyles of Wistar rats weighing 200-250 g (Charles River Laboratories, France). Bone pieces were removed from the defect, and the holes were rinsed with physiological solution $(\mathrm{NaCl} 0.9$ 
$\%(\mathrm{w} / \mathrm{v}))$ before injecting the Hydroxypropyl Methylcellulose (HPMC) gel, containing or not $40 \%(\mathrm{w} / \mathrm{v})$ of calcium phosphate particles, sintered at two different temperatures (i.e. CaP 540 or CaP 570). The PLA membrane, with or without $20 \%(\mathrm{w} / \mathrm{w})$ NPs (as previously described [10]), was used to constrain the gel inside the defect and to start vascularization on the defect side. At 3 and 6 weeks animals were sacrificed by $\mathrm{CO}_{2}$ inhalation and femoral bones were recovered for histological, immunohistochemistry and $\mu \mathrm{CT}$ evaluation. Six independent materials were implanted per tested material and per time point.

\subsection{X-ray microtomography and analysis}

Micro-CT was performed on Explore Locus SP X-ray m-CT devices (General Electric, Milwaukee, WI) ex vivo with a source voltage of $80 \mathrm{kV}$ and a current of $60 \mathrm{~mA}$ to obtain a 15 $\mathrm{mm}$ resolution from $900 \mathrm{X}$-ray radiographs with an exposure time of $3000 \mathrm{~ms}$. After scanning, cross-sectional slices were reconstructed and three-dimensional analysis were performed using eXplore MicroView software (General Electric Healthcare, Milwaukee, WI). Reconstruction of the region of interest was performed after correction of the center of rotation and calibration of mineral density. Each scan was reconstructed using the same calibration system to distinguish bone and air. Bone volume (BV) per total volume (TV) was determined for each sample.

\subsection{Histological analysis}

The femoral and tibial bones were recovered, fixed with $4 \%(\mathrm{w} / \mathrm{v})$ paraformaldehyde for $48 \mathrm{hrs}$ at $4^{\circ} \mathrm{C}$ and then demineralized (Microdec, Diapath, France), dehydrated and embedded in paraffin. Eight microns sections were cut and stained with Masson's Trichrome for osteoid staining, using standard protocols, and observed under a photomicroscope (Nikon eclipse 80i, The Netherlands).

\subsection{Immunohistochemistry analysis}


Immunohistochemistry for CD31 was performed as follows. Eight-micron paraffin sections were cut, deparafinized, rehydrated using ethanol gradients and placed in PBS. Antigen recovery was performed using a proteinase K (Roche, France) digestion procedure and then endogenous peroxidase was quenched using 3\%(v/v) hydrogen peroxide for $5 \mathrm{~min}$ at room temperature (RT). Tissues were blocked with $2 \%$ horse serum, in PBS, for $30 \mathrm{~min}$ at RT. Primary antibody against CD31 (NB100-2284, Novus Biologicals, Bio-Techne, France) was used at 1:100 in $2 \%(\mathrm{w} / \mathrm{v}) \mathrm{BSA}$ in PBS, and incubated overnight at $4^{\circ} \mathrm{C}$. After two washes with PBS, the anti rabbit Impress kit (VectorLabs, USA) was used according to the manufacturer's instructions. Specific staining was obtained using the 3,3'-diaminobenzidine staining solution (VectorLabs, USA). Counterstaining was performed using Mayer's haematoxylin. Samples were then mounted using Pertex medium (Sigma). Sample imaging was performed using a microscope (Nikon Eclipse 80i) equipped with a digital camera (Nikon Dxm 1200C). Sample analysis was performed at three different sample positions and a total of six animal samples were assessed per time point and condition. For vessel quantification the total number of micro vessels was determined and normalized to the area of the defect.

\subsection{Statistical analysis}

Using the Graphpad Prism 5.0 software, a D’Agostino and Pearson omnibus normality test was used in order to test if data obeyed to a Gaussian distribution. Statistically significant differences between several groups were analyzed by the non-parametric Kruskal-Wallis test, followed by a Dunns post-test. The non-parametric Mann-Whitney test was used to compare two groups. A $p$ value lower than 0.05 was considered to be statistically significant.

\section{Results}

\subsection{Biomaterial synthesis and characterization}


Differential thermal analysis (DTA) is a powerful tool when considering sol-gel glasses analysis, due to the ability to evaluate the chemical changes that occur during the calcination steps. Figure 1A displays the DTA plot for the sol-gel material, and in this representation, exothermic reactions correspond to a downward peak on the y-axis. The gravimetric portion of this plot is characterized by a series of downward steps, as materials are burned away during calcination. These downward steps correspond with peaks in the thermometric plot, signifying a chemical change in the sample. The major events in the sol-gel material include a small mass loss and exothermic peak at around $130^{\circ} \mathrm{C}$, which corresponds to the loss of residual water from the material, and then two endothermic peaks at about 250 and $320^{\circ} \mathrm{C}$ as the organic residues are eliminated. Indeed, and as observed in Table 1, residual carbon content was below $0.1 \%$, consistent with the DTA results. Additionally, glass transition temperature (Tg) was $480^{\circ} \mathrm{C}$ in both cases and composition, measured by energy dispersive X-ray spectroscopy (EDS), was as expected (Table 1). In order to analyze the formation of the crystalline phase after the calcination of the sol-gel material, an X-ray powder diffraction (XRD) evaluation was performed. Figure 1B shows how the final amount of crystallization within the material is closely related to the temperature of calcination. Here, all sol-gel samples are compared at the 4 different temperatures treated. Corresponding to the step-wise increase of calcination temperature, each subsequent material exhibits an increase in crystallinity. The sample calcined at $500{ }^{\circ} \mathrm{C}$ had a completely amorphous behavior, and presented a dark grey color associated to a high carbon content. As such, this sample formulation was discarded from further studies.

BET surface area analysis is showed in table 1: $3.41 \pm 0.03$ and $3.60 \pm 0.02 \mathrm{~m}^{2} / \mathrm{g}$ respectively.for 540 and $570^{\circ} \mathrm{C}$ calcined samples respectively.

The one calcined at $540^{\circ} \mathrm{C}(\mathrm{CaP} 540)$ still contains a large amorphous phase, while the powder calcined at $610^{\circ} \mathrm{C}(\mathrm{CaP} 610)$ is completely crystalline. Compounds visible in the sol-gel glass ceramic samples include pyrophosphates, both $\alpha\left(\alpha-\mathrm{Ca}_{2} \mathrm{P}_{2} \mathrm{O}_{7}\right.$, JCPDS 9-345) and $\beta\left(\beta-\mathrm{Ca}_{2} \mathrm{P}_{2} \mathrm{O}_{7}\right.$, 
JCPDS 9-346), as well as a calcium metaphosphate ( $\left.\delta-\mathrm{Ca}\left(\mathrm{PO}_{3}\right)_{2}, \mathrm{JCPDS} 9-363\right)$ and a singular sodium-titanium phosphate $\mathrm{NaTi}_{2}\left(\mathrm{PO}_{4}\right)_{3}$ (JCPDS 84-2008) (Figure 1B).

Figure 2A displays the calcium ion release results for the material, in which total ion release is summed over time. Glass-ceramic particles demonstrated a linear release rate, over the entire time frame investigated. Additionally, the plot shows that with increased sample calcination temperature there is a decrease in the solubility of the ceramic, due to the increased crystallinity of the final product. Respectively, the three sol-gel samples $\mathrm{CaP} 540$, CaP 570 and $\mathrm{CaP} 610$ exhibited linear release rates of $0.065,0.054$ and $0.029 \mathrm{mM} / \mathrm{day}$.

As observed in Figure 2B, pH remained very closed to physiological one in the glass-ceramic environment, for the 3 tested CaPs. Nonetheless, due to the slow release kinetics of CaP 610 sample, we focused on the $\mathrm{CaP} 540$ and CaP 570 bioglass formulations in the following studies.

Figures 2A and 2B, show the micrography of both CaP 540 and CaP 570 showing a nanoscaled crystal particle sizes connected by sintering.

\subsection{In vitro evaluation}

To test the application of these matrices to bone tissue regeneration and to support angiogenesis we initially tested the influence of the composite biomaterial over human PDECs cell viability. As showed in Figure 3A, no significant differences could be observed for both $\mathrm{CaP}$ formulations, in relation to the control. Additionally, and as means to assess the impact of the composite formulation over the expression of VEGF, we performed an ELISA assay to determine the VEGF secretion by PDECs after 4 days of exposure, using a transwell system. As showed in Figure 3B, a significant increase of VEGF secretion was observed for the CaP 540 composite formulation, in relation with the control. 


\subsection{In vivo evaluation}

To determine the capacity of the developed composites to sustain bone repair we focused on a bone defect model in the rat condyle. For this purpose, the two developed composite injectable hydrogels, based on sintered $\mathrm{CaP} 540$ or $\mathrm{CaP} 570$ and dispersed in a HPMC hydrogel, were placed in the defect and covered with an electropsun PLA membrane (with or without $20 \%$ $(\mathrm{w} / \mathrm{w})$ of $\mathrm{CaP}$ particles) as previously reported [10]. Bone regeneration was evaluated at 3 and 6 weeks post-implantation using micro CT based 3D reconstruction and histologic evaluation. As observed in Figure 4A, micro CT imaging shows improved calcified tissue formation for the composite formulations containing CaP materials, in relation to HPMC and PLA alone, and at both time points evaluated. These results are confirmed by micro CT quantification of the mineral volume/total volume ratio (BV/TV) for the explanted femurs (Figure 4B). A significant improvement on $\mathrm{BV} / \mathrm{TV}$ was observed for the HPMC CaP 540, at 3 weeks, in relation with HPMC PLA alone. Also, at 6 weeks post implantation both formulations containing CaP particles (i.e. HPMC, CaP 540 and CaP 570 with PLA membrane 20\% Nps) showed significant improved BV/TV, when compared with HPMC PLA alone.

Micro-CT evaluation was then complemented using histologic evaluation. As observed in Figure 5, significant osteoid tissue formation could be observed in the case of the formulations containing CaP particles, at both 3 and 6 weeks, and consistent with the results obtained from micro-CT analysis. Also, one can observe that for the two formulations containing $\mathrm{CaP}$ particles an increased formation of osteoid tissue (red staining inside the defect) was formed, associated with the deposition of a collagenous matrix (green staining inside the defect, when compared with HMPC and PLA alone (Figure 5).

In view of evaluating the impact of the different formulations, containing $\mathrm{CaP}$ particles sintered 
at two distinct temperatures (i.e. HPMC, $\mathrm{CaP} 540$ and $\mathrm{CaP} 570$ ), on the formation of angiogenesis, we performed an immunohistochemistry for CD31 at 3 and 6 weeks post implantation in a rat condylar defect model. As observed in Figure 6, CD31 immunostaining revealed the existence of vessels inside the defect at both 3 and 6 weeks post implantation. The vessel distribution was homogeneous throughout the defect, being visible both at the center and at the periphery, inside the defect.

As means to quantify the influence of both the presence of $\mathrm{CaP}$ particles within the composite material and of the $\mathrm{CaP}$ sintering temperature on angiogenesis we performed vessel quantification inside the defect. As observed in Figure 7, and although no significant differences could be observed at 3 weeks, at 6 weeks post implantation a significant increase for vessel density could be observed for the defects implanted with HPMC containing CaP 540 particles and covered with PLA membranes, containing $\mathrm{CaP}$, in relation to HPMC and PLA alone. 


\section{Discussion}

Autologous bone grafts are still the gold standard when considering the regeneration of bone defects. Nonetheless, they are associated with several drawbacks, including limited graft availability, increased risk of infection and significant morbidity at the donor site [16]. In this sense, bone tissue engineering approaches have been proposed as promising alternatives, but in spite of tremendous effort and important advances achieved in the last two decades they have not yet fulfilled their promise [17]. One of the major problematic associated with the efficient translation of bone tissue engineering is the inefficient vascularization of both the implanted constructs and the defect site [6]. In this regard, growing interest has been focused on the development of bioactive biomaterials that can modulate the angiogenesis process, during bone tissue regeneration. Recently, we have shown the potential of electrospun poly(lactic acid) (PLA) fiber-based membranes, containing calcium phosphate ormoglass $(\mathrm{CaP})$ particles, to elicit angiogenesis in vivo, in a subcutaneous model in mice [10]. In order to apply this principle to a bone regeneration scenario, here we developed a two component biomaterial approach: 1) a contention membrane of electrospun PLA, containing $20 \%(\mathrm{w} / \mathrm{w})$ of CaP particles, that was previously optimized [10]; and 2) an injectable gel composed of a new generation of $\mathrm{CaP}$ ormoglasses, dispersed at $40 \%(\mathrm{w} / \mathrm{v})$ in a HPMC gel.

HPMC is a derivate polymer of cellulose that has shown to exhibit suitable biological characteristics and that has already been used for the formulation of fast dissolution injectable biomaterial matrices, containing calcium phosphate ceramics [18-20].

Our first approach was to optimize the conditions of $\mathrm{CaP}$ particle production, focusing on their ration of glass/ceramic character, in order to tune their degradation rate and obtain a sustained calcium release profile. As expected, a significant mass loss was observed during the first step 
of calcination, up to $350^{\circ} \mathrm{C}$, where the material lost nearly $40 \%$ in terms of mass. These results were in agreement with previous reports of sol-gel synthesis of phosphate glasses [21, 22], where at $350^{\circ} \mathrm{C}$ the vast majority of the water and extraneous organic material can be eliminated, as shown in Table 1.

The use of different calcination temperatures, over the Tg (Table 1), shows the appearance of different crystal phases (Figure 1B), such as pyrophosphates and the polymorph $\gamma$ of the tricalcium phosphate. These compounds, as well as the notable absence of calcium-phosphates, have shown to be characteristic of phosphate-based sol-gel and melted glasses [12]. Additionally, the presence of a $\mathrm{NaTi}_{2}(\mathrm{PO} 4)_{3}$ peak shows that in spite of the small quantity used, an efficient inclusion of both titanium and sodium, into the crystalline network, was achieved. Also, and although the ratios of these compounds remain similar throughout the heating process, higher processing temperature show to favor the $\beta$-calcium pyrophosphate phase. As previously mentioned, the aim was to achieve a blend of both glassy and crystalline $\mathrm{CaP}$ ormoglass, as such and due to the high crystallinity of the formulation calcinated at $610^{\circ} \mathrm{C}$, this last was discarded from further studies.

On of the limitations regarding glassy materials resides on their fast degradation, after immersion in fluid, and therefore accelerated release of ions in the first several days, before flattening out to a relatively slow release rate [23]. Conversely, we show that by introducing a nanocrystalline phase we could achieve a constant calcium release rate. This approach allows to tune the release profiles, while maintaining the advantageous zero-order release. Additionally, and in contrast to glassy calcium phosphates materials that usually exhibit a dramatic and immediate $\mathrm{pH}$ drop, due to the burst release mechanism [23], our approach shows little $\mathrm{pH}$ variation, over the entire time course. This presents an added value for these materials as significant acidifications has shown to induce osteoblast cell death and pro-inflammatory 
cytokine release by osteoblastic cells [24]. Regarding BET values showed in table 1, difference is too small to obtain any relevant conclusion related to the calcium release profiles

Nonetheless, the thermic process used, necessary to eliminate organics and nucleate the crystal nanophases, shows particle sintering due to the high atomic diffusion. Alternative processes can be used to avoid this issue such as the modification of the thermodynamic stability by altering some experimental conditions or using methods such as spray pyrolysis to avoid the physical contact among particles during the phase's growth.

Following the establishment of two ormoglass formulations, calcined at $540{ }^{\circ} \mathrm{C}$ and $570^{\circ} \mathrm{C}(\mathrm{CaP}$ 540 and $\mathrm{CaP} 570$, respectively), and based on previous reports [19, 20], we formulated them at $40 \%(\mathrm{w} / \mathrm{v})$ in a $2 \%(\mathrm{w} / \mathrm{v})$ HPMC gel. In vitro tests confirm their lack of toxicity for PDECs, under the test conditions, and show a dependence of the calcination temperature on their capacity to elicit VEGF secretion. The HPMC gels containing $40 \%(\mathrm{w} / \mathrm{v})$ of $\mathrm{CaP}$, sintered at $540{ }^{\circ} \mathrm{C}(\mathrm{CaP} 540)$ showed the better performance in terms of VEGF secretion. This correlates well with our previous studies were it was demonstrated that $\mathrm{Ca}^{2+}$ release from ormoglass particles, in the range of $0.6-1 \mathrm{mM}$, induced expression of VEGF gene and protein secretion $[10,25]$

Then, focusing on the application of these composites for bone repair we evaluated their capacity to sustain bone repair in a condylar defect model in rat. Significant improvement in terms of $\mathrm{BV} / \mathrm{TV}$ was observed for the $\mathrm{CaP} 540$ formulation, at 3 weeks, and for both $\mathrm{CaP} 540$ and $\mathrm{CaP} 570$ formulations, at 6 weeks, in relation to the vehicle alone. These results are in line with the $\mathrm{Ca}^{2+}$ release kinetics of both the $\mathrm{CaP} 540$ and CaP570 formulations, where a faster $\mathrm{Ca}^{2+}$ release (i.e. CaP 540 formulation) shows to favor a faster bone repair, evident by micro CT analysis and by the formation of osteoid tissue. Previous studies have indeed shown that elevated $\mathrm{Ca}^{2+}$ levels could promote the recruitment of bone marrow progenitor cells in vivo [26, 27], regulate both bone morphogenetic protein and type I collagen synthesis by osteoblastic 
cells [28] and modulate the osteoinduction of mesenchymal stem cells [29]. Additionally, we and others, have shown that bioactive glasses sustain the expression of proangiogenic cytokines and indirectly induce angiogenesis in vitro $[25,30]$ and in vivo $[10]$. The in vitro mechanism of action of these bioactive ormoglasses has been associated with the degradation of the CaP, leading to the release of physiologically relevant amounts of ions in the extracellular media [3032].

As extracellular calcium has shown important roles both on proliferation, chemotaxis and differentiation of cells, and as elevated calcium levels have been described in the extracellular fluids of tissues suffering remodeling [33], namely bone, it has been proposed that increased calcium levels may act as paracrine regulators for various cellular functions.

Indeed, in the same line of we have recently shown [10], the injectable composite, containing $40 \%$ of ormoglasses cancined at $540{ }^{\circ} \mathrm{C}(\mathrm{CaP} 540)$, shows a significant improvement in terms of angiogenesis. We assume that due to its faster $\mathrm{Ca}^{2+}$ release kinetics, in relation to the ormoglasses sintered at $570{ }^{\circ} \mathrm{C}(\mathrm{CaP} 570)$, it enables the release of $\mathrm{Ca}^{2+}$ in a range suitable for both improved osteogenesis and angiogenesis.

Altogether, one can assume that local elevated calcium levels may induce the recruitment of cells able to favor both a pro angiogenic milieu and to sustain bone formation. This approach allows in a simple and cost effective manner to address both the promotion of bone repair and to sustain angiogenesis.

\section{Conclusions}

We have developed an injectable composite, containing a CaP glass-ceramic dispersed within a HPMC matrix, with the capacity to release calcium in a controlled fashion. We show that by tuning the release of calcium, in vivo, we could improve both bone formation and also increase 
angiogenesis. This methodology allows integrating two fundamental processes for bone tissue regeneration while using a simple, cost effective and safe approach.

\section{References}

[1] Brown KL, Cruess RL. Bone and cartilage transplantation in orthopaedic surgery. A review. J Bone Joint Surg Am 1982;64:270-9.

[2] Damien CJ, Parsons JR. Bone graft and bone graft substitutes: a review of current technology and applications. J Appl Biomater 1991;2:187-208.

[3] Ebraheim NA, Elgafy H, Xu R. Bone-graft harvesting from iliac and fibular donor sites: techniques and complications. J Am Acad Orthop Surg 2001;9:210-8.

[4] St John TA, Vaccaro AR, Sah AP, Schaefer M, Berta SC, Albert T, Hilibrand A. Physical and monetary costs associated with autogenous bone graft harvesting. Am J Orthop (Belle Mead NJ) 2003;32:18-23.

[5] Delloye C, Cornu O, Druez V, Barbier O. Bone allografts: What they can offer and what they cannot. J Bone Joint Surg Br 2007;89:574-9.

[6] Amini AR, Laurencin CT, Nukavarapu SP. Bone tissue engineering: recent advances and challenges. Crit Rev Biomed Eng 2012;40:363-408.

[7] Nguyen LH, Annabi N, Nikkhah M, Bae H, Binan L, Park S, Kang Y, Yang Y, Khademhosseini A. Vascularized bone tissue engineering: approaches for potential improvement. Tissue Eng Part B Rev 2012;18:363-82.

[8] Carragee EJ, Hurwitz EL, Weiner BK. A critical review of recombinant human bone morphogenetic protein-2 trials in spinal surgery: emerging safety concerns and lessons learned. Spine J 2011;11:471-91.

[9] Laschke MW, Harder Y, Amon M, Martin I, Farhadi J, Ring A, Torio-Padron N, Schramm R, Rucker M, Junker D, Haufel JM, Carvalho C, Heberer M, Germann G, Vollmar B, Menger MD. Angiogenesis in tissue engineering: breathing life into constructed tissue substitutes. Tissue Eng 2006;12:2093-104.

[10] Oliveira H, Catros S, Boiziau C, Siadous R, Marti-Munoz J, Bareille R, Rey S, Castano O, Planell J, Amedee J, Engel E. The proangiogenic potential of a novel calcium releasing biomaterial: Impact on cell recruitment. Acta Biomater 2016;29:435-45.

[11] Aguirre A, Gonzalez A, Planell JA, Engel E. Extracellular calcium modulates in vitro bone marrow-derived Flk-1+CD34+ progenitor cell chemotaxis and differentiation through a calcium-sensing receptor. Biochem Biophys Res Commun 2010;393:156-61.

[12] Navarro M, del Valle S, Martinez S, Zeppetelli S, Ambrosio L, Planell JA, Ginebra MP. New macroporous calcium phosphate glass ceramic for guided bone regeneration. Biomaterials 2004;25:4233-41.

[13] Sanzana ES, Navarro M, Macule F, Suso S, Planell JA, Ginebra MP. Of the in vivo behavior of calcium phosphate cements and glasses as bone substitutes. Acta Biomater 2008;4:1924-33.

[14] Thebaud NB, Bareille R, Remy M, Bourget C, Daculsi R, Bordenave L. Human progenitorderived endothelial cells vs. venous endothelial cells for vascular tissue engineering: an in vitro study. J Tissue Eng Regen Med 2010;4:473-84.

[15] Repetto G, del Peso A, Zurita JL. Neutral red uptake assay for the estimation of cell viability/cytotoxicity. Nat Protoc 2008;3:1125-31.

[16] Frohlich M, Grayson WL, Wan LQ, Marolt D, Drobnic M, Vunjak-Novakovic G. Tissue engineered bone grafts: biological requirements, tissue culture and clinical relevance. Curr Stem Cell Res Ther 2008;3:254-64.

[17] Woodruff MA, Lange C, Reichert J, Berner A, Chen F, Fratzl P, Schantz J-T, Hutmacher DW. Bone tissue engineering: from bench to bedside. Materials Today 2012;15:430-5. 
[18] Gauthier O, Boix D, Grimandi G, Aguado E, Bouler JM, Weiss P, Daculsi G. A new injectable calcium phosphate biomaterial for immediate bone filling of extraction sockets: a preliminary study in dogs. J Periodontol 1999;70:375-83.

[19] Weiss P, Gauthier O, Bouler JM, Grimandi G, Daculsi G. Injectable bone substitute using a hydrophilic polymer. Bone 1999;25:67S-70S.

[20] Weiss P, Layrolle P, Clergeau LP, Enckel B, Pilet P, Amouriq Y, Daculsi G, Giumelli B. The safety and efficacy of an injectable bone substitute in dental sockets demonstrated in a human clinical trial. Biomaterials 2007;28:3295-305.

[21] Pickup DM, Abou Neel EA, Moss RM, Wetherall KM, Guerry P, Smith ME, Knowles JC, Newport RJ. Ti K-edge XANES study of the local environment of titanium in bioresorbable TiO2CaO-Na2O-P2O5 glasses. J Mater Sci Mater Med 2008;19:1681-5.

[22] Pickup DM, Guerry P, Moss RM, Knowles JC, Smith ME, Newport RJ. New sol-gel synthesis of a (CaO)0.3(Na20)0.2(P2O5)0.5 bioresorbable glass and its structural characterisation. Journal of Materials Chemistry 2007;17:4777-84.

[23] Castano O, Sachot N, Xuriguera E, Engel E, Planell JA, Park JH, Jin GZ, Kim TH, Kim JH, Kim HW. Angiogenesis in bone regeneration: tailored calcium release in hybrid fibrous scaffolds. ACS Appl Mater Interfaces 2014;6:7512-22.

[24] Lee GH, Hwang JD, Choi JY, Park HJ, Cho JY, Kim KW, Chae HJ, Kim HR. An acidic pH environment increases cell death and pro-inflammatory cytokine release in osteoblasts: the involvement of BAX inhibitor-1. Int J Biochem Cell Biol 2011;43:1305-17.

[25] Aguirre A, Gonzalez A, Navarro M, Castano O, Planell JA, Engel E. Control of microenvironmental cues with a smart biomaterial composite promotes endothelial progenitor cell angiogenesis. Eur Cell Mater 2012;24:90-106; discussion

[26] Adams GB, Chabner KT, Alley IR, Olson DP, Szczepiorkowski ZM, Poznansky MC, Kos CH, Pollak MR, Brown EM, Scadden DT. Stem cell engraftment at the endosteal niche is specified by the calcium-sensing receptor. Nature 2006;439:599-603.

[27] Tommila M, Jokilammi A, Terho P, Wilson T, Penttinen R, Ekholm E. Hydroxyapatite coating of cellulose sponges attracts bone-marrow-derived stem cells in rat subcutaneous tissue. J R Soc Interface 2009;6:873-80.

[28] Nakade 0, Takahashi K, Takuma T, Aoki T, Kaku T. Effect of extracellular calcium on the gene expression of bone morphogenetic protein-2 and -4 of normal human bone cells. J Bone Miner Metab 2001;19:13-9.

[29] Gonzalez-Vazquez A, Planell JA, Engel E. Extracellular calcium and CaSR drive osteoinduction in mesenchymal stromal cells. Acta Biomater 2014;10:2824-33.

[30] Day RM. Bioactive glass stimulates the secretion of angiogenic growth factors and angiogenesis in vitro. Tissue Eng 2005;11:768-77.

[31] Keshaw H, Forbes A, Day RM. Release of angiogenic growth factors from cells encapsulated in alginate beads with bioactive glass. Biomaterials 2005;26:4171-9.

[32] Leu A, Leach JK. Proangiogenic potential of a collagen/bioactive glass substrate. Pharm Res 2008;25:1222-9.

[33] Brown EM, MacLeod RJ. Extracellular calcium sensing and extracellular calcium signaling. Physiol Rev 2001;81:239-97.

\section{Figure legends}

Figure 1. A) Differential thermal analysis (DTA) plot of the sol-gel material. DTA is represented by the solid line with the left axis, while the mass change trace is displayed by a 
dotted line and corresponds to the right axis. B) X-ray powder diffraction (XRD) and phase composition comparison of the sol-gel materials calcined at different temperatures $\left({ }^{\circ} \mathrm{C}\right)$ a) 610 (CaP 610), b) 570 (CaP 570), c) $540(\mathrm{CaP} 540)$ and d) $500{ }^{\circ} \mathrm{C}(\mathrm{CaP} 500)$.

Figure 2. A) $\mathrm{Ca}^{2+}$ release and $\mathrm{B}$ ) $\mathrm{pH}$ evaluation from samples calcined at 3 different temperatures and the G5 standard previously reported. C) and D) are representative micrographies by FE-SEM of nanostructured agglomerates resulting from the glass-ceramic fabrication.

Figure 3. A) Percent cell viability, as measured by the neutral red assay, of human progenitorderived endothelial cells (PDECs) exposed for $24 \mathrm{hr}$ to (Hydroxypropyl) methyl cellulose (HPMC) gels containing $40 \%(\mathrm{w} / \mathrm{v})$ of calcium phosphate particles $(\mathrm{CaP})$, sintered at two different temperatures (i.e. $540(\mathrm{CaP} 540)$ or $\left.570{ }^{\circ} \mathrm{C}(\mathrm{CaP} 570)\right)$ and normalized in relation to the control (Average $\pm \mathrm{SD}, \mathrm{n}=8, *$ and NS denotes $\mathrm{p}<0.05$ or non significant, respectively). B) Quantification of vascular endothelial growth factor (VEGF) expression by PDECs cultured with exposure, during 4 days, to HPMC gels containing $40 \%(\mathrm{w} / \mathrm{v})$ of $\mathrm{CaP}$, sintered at $540{ }^{\circ} \mathrm{C}$ $(\mathrm{CaP} 540)$ or $570{ }^{\circ} \mathrm{C}(\mathrm{CaP} 570)(\mathrm{n}=4$, average $\pm \mathrm{SD} ; *$ and $\mathrm{NS}$ denotes $p<0.05$ or non significant, respectively).

Figure 4. A) Micro-CT representative evaluation of bone formation inside the condylar bone defects when filled with (Hydroxypropyl) methyl cellulose (HPMC) gels containing 40\% (w/v) of calcium phosphate particles $(\mathrm{CaP})$, sintered at two different temperatures (i.e. 540 (CaP 540) or $\left.570{ }^{\circ} \mathrm{C}(\mathrm{CaP} 570)\right)$, and covered with PLA, alone, or containing $20 \% \mathrm{CaP}$ particles, at 3 and 6 weeks post implantation (scale $=2 \mathrm{~mm}$ ). B) Quantitative assessment of Bone volume/total 
volume (BV/TV), by micro-CT evaluation, inside the condylar bone defects when filled with HPMC gels containing $40 \%(\mathrm{w} / \mathrm{v})$ of $\mathrm{CaP}$ particles, sintered at $540{ }^{\circ} \mathrm{C}(\mathrm{CaP} 540)$ or $570{ }^{\circ} \mathrm{C}$ (CaP 570), and covered with PLA, alone, or containing 20\% CaP particles, at 3 and 6 weeks post implantation. (Average $\pm \mathrm{SD}, \mathrm{n}=6, * *, * * *$ and NS denote $p<0.01, p<0.001$ and non significant, respectively).

Figure 5 Masson's Trichrome staining of histological sections of the condylar bone defects when filled with (Hydroxypropyl) methyl cellulose (HPMC) gels containing 40\% (w/v) of calcium phosphate particles $(\mathrm{CaP})$, sintered at two different temperatures (i.e. $540{ }^{\circ} \mathrm{C}(\mathrm{CaP} 540)$ or $\left.570{ }^{\circ} \mathrm{C}(\mathrm{CaP} 570)\right)$, and covered with PLA, alone, or containing $20 \% \mathrm{CaP}$ particles, at 3 and 6 weeks post implantation (scale $=1000 \mu \mathrm{m})$.

Figure 6. CD31 immunohistochemistry of histological sections of the condylar bone defects when filled with HPMC and covered with PLA alone (A1, A2 and D1, D2), or containing CaP particles sintered at $540{ }^{\circ} \mathrm{C}\left(\mathrm{CaP} 540, \mathbf{B 1}, \mathbf{B 2}\right.$ and E1, E2) or $570{ }^{\circ} \mathrm{C}(\mathrm{CaP} 540, \mathbf{C 1}, \mathbf{C 2}$ and F1, F2) and covered with PLA containing 20\% CaP particles, at 3 (A-C) and 6 (D-F) weeks post implantation (scale $=1000 \mu \mathrm{m}$ for A1-F1 or scale $=100 \mu \mathrm{m}$ for A2-F2). Blood vessels identified by arrows.

Figure 7. Quantification of vessel density inside the condylar bone defects when filled with HPMC and covered with PLA alone, or containing CaP particles sintered at $540{ }^{\circ} \mathrm{C}(\mathrm{CaP} 540)$ or $570{ }^{\circ} \mathrm{C}(\mathrm{CaP} 570)$ and covered with PLA containing $20 \% \mathrm{CaP}$ particles, at 3 and 6 weeks post implantation (scale $=20 \mu \mathrm{m} ; \mathrm{n}=6$, average $\pm \mathrm{SD} ; *$ and NS denotes $p<0.05$ and non significant, respectively). 


\section{Tables}

Table 1. Glass transition temperature (Tg), Carbon final content, and oxide based composition of the glass ceramic calcined at $540{ }^{\circ} \mathrm{C}(\mathrm{CaP} 540)$ and $570{ }^{\circ} \mathrm{C}(\mathrm{CaP} 570)$ (average $\left.\pm \mathrm{SD}\right)$.

\begin{tabular}{|c|c|c|c|c|c|c|}
\hline & Tg & $\begin{array}{c}\text { Carbon Content } \\
(\mathrm{at} \%)\end{array}$ & $\begin{array}{c}\text { BET Surface } \\
\text { Area }\left(\mathrm{m}^{2} / \mathrm{g}\right)\end{array}$ & $\mathrm{CaO}$ & $\mathrm{P}_{2} \mathrm{O}_{5}$ & $\mathrm{Na}_{2} \mathrm{O}$ \\
\hline & & & & & \\
\hline
\end{tabular}

